\title{
Correspondence
}

\section{Proliferative diabetic retinopathy}

\author{
To the Editor of the British Journal of Ophthalmology
}

SIR, I have read with great interest the correspondence between Phillips (r973) and Dobree \& Taylor (r973). Phillips correctly warns of the dangers of both observer and patient bias. "The desire for successful outcome is felt so strongly by both patient and investigator that objectivity cannot be guaranteed" (Cox, I968). Observer bias, which can work either for or against the experimental treatment, can in the case of visual acuity, as Phillips points out, be prevented by keeping the refractionist unaware of who was treated and who was a control. Sham procedures are not always ethically justified, but this does not relieve the clinical investigator of the responsibility of taking patient bias into account. Patient bias in visual acuity can be counteracted by cajoling the patient to a maximum effort and by attempting to measure the magnitude of any residual bias (Aiello and others, in press).

Alternating patients is not satisfactory a substitute for randomization because the investigator knows whether a treated subject or a control is coming next. Having this knowledge he can elect to admit or reject the next patient, and the resulting bias can damage the integrity of the study.

Symmetrical eyes provide greater precision of the estimated treatment effect in a treatment comparison study than asymmetrical eyes. However, symmetry of paired eyes is not necessary for randomization. If it were, then one could not randomize unpaired eyes (if eyes were the sampling unit) or unpaired patients (if patients were the sampling unit). Many clinical trials in which heterogeneous patients remained unpaired have been carried out successfully. The main purpose of randomization, which it accomplishes without sacrificing precision, is to eliminate selection biases. Precision can be increased by pairing (Ederer, I973) or stratifying (Hill, 1962), and also, of course, by increasing sample size.

Dobree and Taylor say that they excluded a statistical analysis because "it is not known if the disease existed in comparable severity in the treated and untreated cases; many of the local and general factors influencing the prognosis are still unknown'. I believe it is safe to predict that all the prognostic factors will never be known. But knowledge of prognostic factors is not necessary for the design of a meaningful clinical trial. Both the efficacy of the Salk vaccine for preventing poliomyelitis and the inefficacy of antihistamines in treating the common cold were determined by randomized, double-masked studies without much, if any, knowledge about prognostic factors.

If a statistical analysis cannot be justified, then no generalization of Dobree and Taylor's finding, "Using the parameters of the retention of the visual acuity, the treated cases fared better than the control cases ..." is warranted. For, as Weaver (1960) said, "Statistical evidence is, in essentially all nontrivial cases, the only sort of evidence we can possibly have'.

I am deriving more than a whit of satisfaction in returning across the Atlantic lessons in experimental design and statistical analysis taught by Fisher (1935), who discovered randomization as the nonpareil method of preventing bias in allocating treatments, and Hill (1962), father of the modern clinical trial.

Yours faithfully, Fred EDERER Head, Section on Clinical Trials and Natural History Studies,

NATIONAL INSTITUTES OF HEALTH, National Eye Institute

BETHESDA, MARYLAND 20014 USA

March 2I, 1974

\section{References}

AIEllo, L. M., et al. (in press) Arch. Ophthal. (Chicago), Letter to the Editor cox, K. R. (1968) "Planning Clinical Experiments". Thomas, Springfield, Ill.

DOBReE, J. H., and TAYLOR, E. (1973) Brit. J. Ophthal., 57, 874

EDERER, F. (1973) Arch. Ophthal. (Chicago), 89, I (Editorial)

FISHER, R. A. (1935) "The Design of Experiments". Hafner Publishing Company, New York

HILl, A. B. (1962) "Statistical Methods in Clinical and Preventive Medicine", Chapters I, 2, 3. Livingstone,

Edinburgh and London

PHILlips, c. I. (1973) Brit. 7. Ophthal., 57, 873

WEAVER, W. (1960) Science, 132, I859 